http://jmscr.igmpublication.org/home/

ISSN (e)-2347-176x ISSN (p) 2455-0450

crossref DOI: https://dx.doi.org/10.18535/jmscr/v7i10.92

Journal Of Medical Science And Clinical Research

\title{
A Rare Presentation of Adult tropical Pyomyositis with Paget Schroetter Syndrome
}

\author{
Authors \\ Dr Ashiti Jain ${ }^{1}$, Dr Vandana Dandekar ${ }^{2}$, Dr Jaishree Ghanekar ${ }^{3}$ \\ ${ }^{1}$ Junior Resident, Internal Medicine, ${ }^{2}$ Assistant Prof, Internal Medicine \\ ${ }^{3}$ Prof \& Head, Dept of Internal Medicine \\ MGM Medical College and Hospital, Navi Mumbai, Maharashtra, India
}

\begin{abstract}
Reporting a case of 25 year male, labourer, who presented in ER with complaints of acute onset shortness of breath with orthopnoea, right sided chest pain. On admission patient had tachycardia, hypotension with erythema and tenderness present over right side of chest. The events followed after pulling a $60 \mathrm{~kg}$ load manually. B/l lower limb doppler was s/o DVT. Right upper limb Doppler was suggestive of thrombus in right IJV and Subclavian vein. Mri right shoulder revealed multiple abscess in muscles of right shoulder and back. The abscess was drained by the surgical team and culture and sensitivity grew staphylococcus aureus thereby confirming the diagnosis of tropical pyomyositis with pagetschroetter syndrome.

Tropical pyomyositis is a disease of tropical countries, which is characterised by suppuration within skeletal muscles, presenting as single or multiple abscesses. The diagnosis is confirmed either by aspiration of pus from the affected muscles or biopsy. Upper extremity deep vein thrombosis (UEDVT) is seen in approximately 5 to 10 percent of all cases of DVT, classically occurring in the dominant arm of young athletes. The purpose of the case report is to make physicians more familiar with this potentially life threatening but curable infective disease entity.
\end{abstract}

\section{Introduction}

Tropical pyomyositis, also known as MYOSITIS TROPICANS, TROPICAL SKELETAL MUSCLE ABSCESS; is a disease of tropical countries, With increasing recognition from temperate regions, it is also referred to as NONTROPICAL MYOSITIS, INFECTIOUS MYOSITIS, OR SPONTANEOUS BACTERIAL MYOSITIS $^{(1)}$, is characterised by suppuration within skeletal muscles, manifesting as single or multiple abscesses. The most common organism being Staphylococcus aureus. In 20\%-50\% of cases there is a history of trauma to the affected muscles, very common in age 15-30, espatheletes.
Commonly involved muscles listed are quadriceps, glutei, iliopsoas, gastrocnemius, abdominal muscles, spinal muscles, pectoralis major, serratus anterior, abdbiceps. Early diagnosis is often missed because of lack of specific signs, unfamiliarity with the disease, atypical manifestations, and a wide range of differential diagnosis. Diagnostic techniques like USG, CT and MRI are very useful in diagnosis of the disease, further confirmed either by biopsy or aspiration of pus from the affected muscles. Cloxacillin is the $1^{\text {st }}$ antibiotic of choice. Incision and drainage are important part of management. 
Upper extremity deep vein thrombosis (UEDVT) makes up for approximately 5 to 10 percent of all cases of DVT. In the upper extremity, the deep veins include axillary vein, subclavian vein, paired radial, ulnar and brachial veins,. The most common site of UEDVT are the axillary and subclavian veins; howsoever, the more distal brachial vein may also get involved. The internal jugular veins may also be included. UEDVT occurs in primary and secondary forms with the symptom severity and treatment options varying between the two.

Primary UEDVT is less common than secondary UEDVT and is most typically effort-induced, hence known as Paget-Schroetter syndrome (PSS), EFFORT THROMBOSIS, TOS (thoracic outlet syndrome). It mainly occurs in the dominant arm of young athletes. The most commonly use diagnostic modality is venous duplex ultrasonography. Duplex ultrasound mainly shows loss of compressibility of the vein and lack of color Doppler flow within the venous lumen. Secondary UEDVT occurs due to thrombosis as a result of indwelling devices like central venous catheters (CVC), pacemaker or defibrillator leads, and tunneled central access lines. Catheter-associated UEDVT is the most common cause, covering $93 \%$ of all UEDVT.

\section{Case Report}

A 25 year male, coolie, with no pre morbid illness presented to ER with acute onset breathlessness with orthopnoea, Right sided chest pain radiating to back and right shoulder since 3 days, associated with swelling over right side of neck and chest; cough with expectoration- non blood stained. The sequence of events started after pulling a $60 \mathrm{~kg}$ weight with his right hand. No any significant past history. Patient presented to a health care centre in a pulseless state with non recordable BP where he was treated with steroids, inotropes and antibiotics but remained symptomatic. Patient was resuscitated with iv fluids and was referred to our institute. No history of fever or any family history of other coagulopathies. At the time of presentation in ER, patient was afebrile with tachycardia of $156 / \mathrm{min}$, hypotensive with SBP- 80 systolic, tachypneic with RR of $26 / \mathrm{min}$ maintaining saturation of $92 \%$ at room air, RBS$131 \mathrm{mg} / \mathrm{dl}$, with blanching present. Patient had tender, eythematous swelling, approx $4 \times 5 \mathrm{~cm}$ present over anterior and posterior triangle of neck, right supraclavicular region extending over entire right upper limb, which was none pitting in nature. Movements of limb were painful and were slightly restricted. The left upper limb was normal. Respiratory examination revealed decreased right sided chest movements with use of accessory muscles of respiration, air entry decreased in $\mathrm{R}>>\mathrm{L}$, with very fine basal crepts at infrascapular and infra-axilly area. Examination of Cardiovascular and central nervous system was unremarkable. Arterial blood gas analysis showed $\mathrm{PaO} 2 / \mathrm{FiO} 2$ ratio of 600. ECG showed sinus tachycardia. (Fig 1) Chest radiograph showed right lower zone consolidation with pleural effusion. (fig 2)

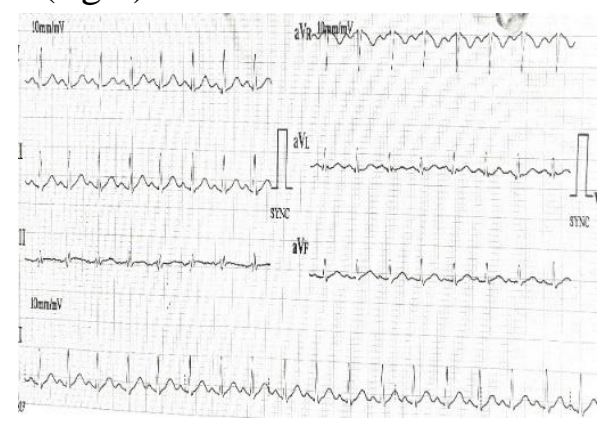

Fig 1

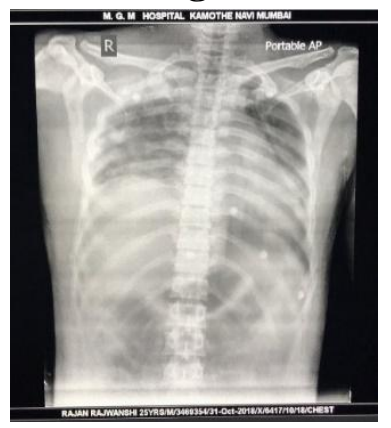

Fig 2

USG CHEST confirmed right sided basal consolidation. His laboratory parameters at the time of presentationis mentioned in table 1.The Quick SOFA score was 2 with a lactate of 3.4 $\mathrm{mmol} / \mathrm{L}$. The differential diagnosis at the time of presentation are outlined in table 2.As per history 
and initial investigations, provisional diagnosis of septic shock with ARDS vs. pulmonary embolism was made with source of sepsis yet to be evaluated.

Bilateral LOWER LIMB VENOUS DOPPLER incidentally revealed short segment partial lumen occluding thrombus in short saphenous vein of right lower limb and great saphenous vein of left lower limb.

Wells score for pulmonary embolism was 4.5. CT PULMONARY ANGIOGRAPHY showed multifocal air space consolidation with mild effusion in right lower zone with passive collapse of lower lobe, with myositis and adenitis in adjacent soft tissue on right side, with Main PA$2.5 \mathrm{~cm}$, RPA- $1.4 \mathrm{~cm}$, LPA- $1.3 \mathrm{~cm}$ with No evidence of thromboembolism. No evidence of pulmonary embolism, heart failure, valvular insuuficiency, tamponade, pulmonary artery hypertension in echocardiography with $60 \%$ ejection fraction.

After ruling out pulmonary thromboembolism, Patient was then further evaluated for swelling in right sided chest wall and right upper limb extending upto neck. (fig 3)

Table 1: Laboratory parameters at the time of presentation

\begin{tabular}{|c|c|c|c|c|}
\hline $\begin{array}{l}\text { Outside } \\
\text { inv }\end{array}$ & $27 / 10 / 18$ & $28 / 10 / 18$ & & \\
\hline $\mathrm{Hb}$ & 14.1 & 15.1 & $\begin{array}{c}\text { HIV/HCV/HBs } \\
\mathrm{Ag} \\
\end{array}$ & NR \\
\hline Wbc & 3300 & 3760 & MP & Not detected \\
\hline Plt & 1.28 & 0.94 & RMA & Negative \\
\hline $\mathrm{PcV}$ & & 39.40 & Dengue/lepto & Negative \\
\hline Srbili (T) & & 1.14 & CPKMB & 39.0 \\
\hline Srbili (D) & & 0.44 & CPK TOTAL & 737 \\
\hline Sgot & & 61.7 & $\begin{array}{c}\text { Urine for } \\
\text { myoglobin }\end{array}$ & Negative \\
\hline Sgpt & & 44.2 & TROP T & 7.140 \\
\hline ALP & & 59 & ESR & 12 \\
\hline TPR & & 5.49 & CRP & 291.60 \\
\hline Alb & & 2.38 & & \\
\hline BUN & & 34.6 & PT & 19.1 \\
\hline Urea & & 74.0 & INR & 1.65 \\
\hline Creatinine & 1.7 & 1.19 & APTT & $\begin{array}{c}32.40 \quad(\mathrm{C}- \\
30.40)\end{array}$ \\
\hline Uric acid & & 6.60 & & \\
\hline $\mathrm{Na}$ & & 138 & Urine rm & $\begin{array}{c}\text { Prot 2+/OB 2+ } \\
\text { RBC 10- } \\
\text { 12,PC10-12 }\end{array}$ \\
\hline $\mathrm{K}$ & & 4.5 & & \\
\hline $\mathrm{Cl}$ & & 98.0 & & \\
\hline RBS & 158 & 131 & & \\
\hline
\end{tabular}

Table 2: Differential diagnosis of subacute dyspnoea in background of presumed sepsis

\begin{tabular}{|l|}
\hline Pulmonary embolism \\
\hline ARDS \\
\hline Pneumonia \\
\hline Myocarditis \\
\hline Pneumothorax \\
\hline Shock: septic, hypovolemic, cardiogenic \\
\hline
\end{tabular}

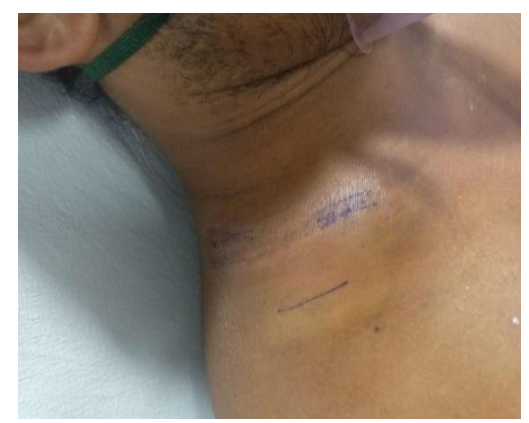

Fig 3

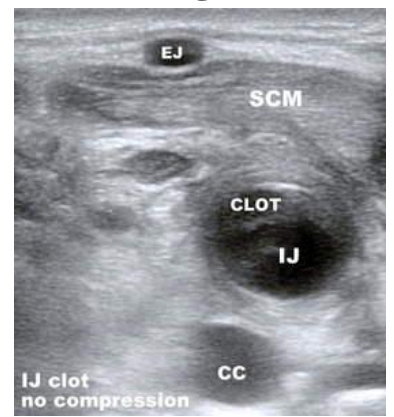

Fig 4 usg local part

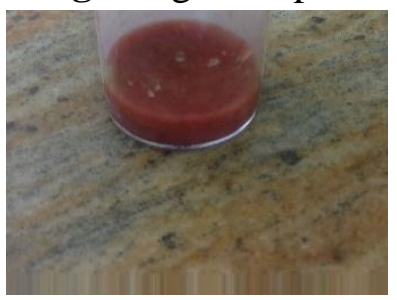

Fig 7 pus aspirated

USG RIGHT CHEST (LOCAL) showed soft tissue edema and cellulitis in subcutaneous compartment, multiple small ongoing collections in INTRAMUSCULAR compartment over right shoulder, arm and pectoralis with necrotic intramuscular LN. A partial lumen occluding thrombus was noted in right IJV.USG NECK showed heteroechoeic predominantly hyperechoic collection in INTRAMUSCULAR plane of right sternocleidomastoid muscle measuring $3.2 \times 0.8 \mathrm{~cm}$ with no e/o vascularity. Inflammatory changesin surrounding muscle with subcutaneous edema was noted in neck region s/o intramuscular abscess. RIGHT UPPER LIMB VENOUS COLOUR 
DOPPLER confirmed Partial lumen occluding acute thrombus segment measuring $1 \times 0.4 \mathrm{~cm}$ in right IJV at the level of thyroid and $4 \mathrm{~cm}$ in right subclavian vein with inflammatory changes in subcutaneous tissue with subcentrimetric LN. (Fig 4) MRI NECK WITH SHOULDER (PLAIN) showed T2/STIR hyper signal intensity collection at right lung apex ms $8.0 \times 4.0 \times 9 \mathrm{~cm}$ (pleural based), loculated collection in left paraspinal region, diffuse collection in b/lparaspinal region, within muscle fibres of right serratus anterior, right posterior cervical space, right paravertebral muscles, right trapezius, and scalene group of muscles on right, right axillary region with loss of fat planes, (fig 6) thereby confirming the diagnosis of pyomyositis with pagetschroetter syndrome.

After reviewing with our Surgical, CVTS and orthopaedic colleagues, a clinical diagnosis of tropical pyomyositis was made. Patient was given limb elevation, cold compression over the swelling.

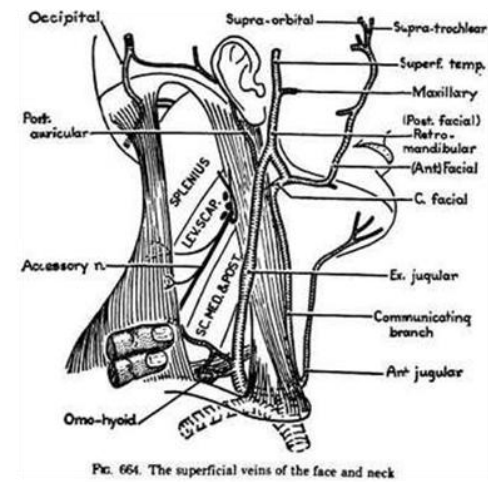

Fig 5: Anatomy of Neck Veins

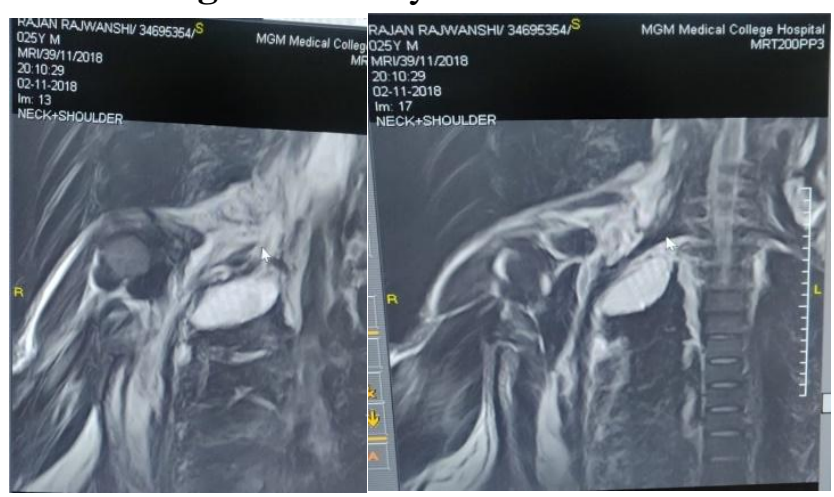

Fig 6 MRI Cervical Spine

Patient's procoagulant profile was sent and patient was put on low molecular weight heparin which was later overlapped with oral anticoagulant (dabigatran), planned for 6 months. After obtaining appropriate samples for cultures (blood, urine), patient was started on broad spectrum antibiotics (cefoperazone- sulbactam, meropenem, metronidazole), hydrocortisone, hydrated with IVF.

Meanwhile, serial scans were done and incision and drainage of right cervical and axillary abscess was planned under short GA. 30-40 ml of frank pus mixed with blood (fig 7) was drained from cervical abscess and $200 \mathrm{ml}$ of pus with oedema fluid was drained from axillary abscess revealing underlying necrotic muscle.

Patient's blood culture grew staphylococcus aureus. Pus culture from cervical and axillary abscess grew staphylococcus aureus. Urine culture was sterile. Patients' prothrombotic profile: PT 19.2

Post op day 1 patient deteriorated clinically as well as biochemically. Patient developed septic shock with multiorgan dysfunction with acute kidney injury with severe anemia secondary to acute blood loss.

Patient became tachypniec, hypoxic, drowsy, disoriented and was put on ventilatory support. PCVs, FFPs, and RDPs were transfused to the patient. In view of continuous bleeding from drainage site, it was re-explored and $200 \mathrm{gms}$ of clots were removed, revealing minute oozing from necrosed muscles. Adrenaline soaked gauze pieces were kept in the cavity with compressive dressing. All measures were taken to stop bleeding. Antibiotics were escalated to clindamycin. Patient was put on inotropic support. Despite all resuscitation measures, patient succumbed to disease.

\section{Discussion}

The uniqueness of the case is defined by the coexistence of swelling of upper limb and respiratory failure in a patient which cannot be explained by a single cause. The presence of deep venous thrombosis in lower limbs made us suspect pulmonary embolism although CTPA excluded significant pulmonary thromboembolic process. The development of fever with hemodynamic 
instability made us suspect development of septic shock due to an untreated septic process which was later confirmed as pyomyositis on USG and MRI. But what seemed out of place was the almost continuous presence of deep vein thrombosis with pyomyositis in upper limb. If the thromboembolic phenomenon was due to the systemic effects of sepsis (the hypothesis initially considered) - why was it present adjacent to the inflamed muscles? It can be explained by the inflammation and compression of the vessel wall either by the pus in the muscle which the MRI confirmed or Hyper-abduction of the arm, especially with sudden jerky movements which can cause repetitive trauma to the vein wall along with mechanical compression by adjoining cervical rib, muscles; thereby initiating thrombus formation. $^{(2)}$

The basic pathophysiology of all septic thromboplebitides, regardless of the vein involved; correlates to Virchow"s triad endothelial dysfunction(due to inflammatory mediators and microbial toxins), stasis of blood (by compression of vein), platelet aggregation and hypercoagulable state (by sepsis). This acts as source of septic emboli, the most common site being lung, leading to pulmonary abscess and empyema (85\%), pneumothorax and ARDS $(10 \%)^{(2)}$

Pyomyositis, mainly found in tropical areas ${ }^{(1,3,4)}$; was first described by Scriba in $1885 .{ }^{(5)}$ The term "tropical pyomyositis" should be restricted to the suppurative primary muscle abscess arising within the skeletal muscle. It should not be used for (a) intermuscular abscesses, (b) abscesses extending into muscles from adjoining tissues such as bone or subcutaneous tissues, and (c) those which develop secondary to previous septicaemia. ${ }^{(1)}$ Tropical pyomyositis is also reported from temperate regions, referred to as non-tropical myositis, infectious myositis, or spontaneous bacterial myositis.(6)
Table 3: Predisposing factors of tropical pyomyositis:

\begin{tabular}{|c|c|}
\hline $\begin{array}{l}\text { Immunodeficient } \\
\text { conditions }\end{array}$ & $\begin{array}{ll}\text { 1. } & \text { T cell deficiency } \\
\text { 2. } & \text { Chronic granulomatous disease } \\
\text { 3. } & \text { Hyper IgE syndrome } \\
\text { 4. } & \text { HIV } \\
\text { 5. } & \text { Malignancy } \\
\text { 6. } & \text { Diabetes } \\
\text { 7. } & \text { Cancer chemotherapy } \\
\text { 8. } & \text { Immunosuppressive drugs after } \\
& \text { transplantation of solid organs } \\
\text { 9. } & \text { Steroids }\end{array}$ \\
\hline Trauma & $\begin{array}{ll}\text { 1. } & \text { Rarely after bicycle accidents }(7,8) \\
\text { 2. } & \text { Vigorous exercise } \\
\end{array}$ \\
\hline $\begin{array}{l}\text { Concurrent } \\
\text { infections }\end{array}$ & $\begin{array}{ll}\text { 1. } & \text { Toxocariasis } \\
\text { 2. } & \text { Varicella } \\
\text { 3. } & \text { Arbovirus } \\
\text { 4. } & \text { Nematode } \\
& \text { (Dracunculusmedinensis). }\end{array}$ \\
\hline Other & $\begin{array}{ll}\text { 1. } & \text { Chronic renal failure } \\
\text { 2. } & \text { Asplenia } \\
\text { 3. } & \text { Scleroderma } \\
\text { 4. } & \text { Rheumatoid arthritis } \\
\text { 5. } & \text { Felty's syndrome } \\
\text { 6. } & \text { Malnutrition } \\
\text { 7. } & \text { Intravenous drug abuse(9) }\end{array}$ \\
\hline
\end{tabular}

The most common organism being Staphylococcus aureus (90\% in tropics and $75 \%$ in temperate areas)(10), Group A streptococcus accounts $(1-5 \%)$. Other organisms include streptococcus (groups B, C, G), pneumococcus, pseudomonas, neisseria, haemophilus, aeromonas, Escherichia, serratia, yersinia, and klebsiella. ${ }^{(10,11)}$ Rarely salmonella, citrobacter, fusobacterium, anaerobes, and mycobacterium are also seen. ${ }^{(12-16)}$ Pyomyositis is a disease of unclear pathogenesis. Skeletal muscle tissue is resistant to bacterial infections under normal circumstances due to sequestration of iron by myoglobin (essential nutrition for growth of bacteria), thereby slowing the growth of bacteria, allowing cellular and humoral defences to invade infected zones and hence prevents development of infection. ${ }^{(17)}$

Damaged muscle becomes susceptible to haematogenous invasion by bacteria with subsequent abscess formation. ${ }^{(18)}$ In $20 \%-50 \%$ of cases, a history of blunt trauma or vigorous exercise of the involved group of muscles is present. ${ }^{(19)}$ It is believed that abundant iron is available after trauma, resulting in profuse growth of bacteria.

It has also been postulated that T-cells, in patients with tropical pyomyositis are not primed 
adequately against staphylococcus during the course of infection. ${ }^{(20)(21)(22)}$

The disease is seen in all age groups, young males being most common. Maximum incidence is at $10-40$ years of age with a M:F ratio of $1.5: 1$. Muscles frequently involved are quadriceps, glutei, pectoralis major, serratus anterior, biceps, iliopsoas, gastrocnemius, abdominal and spinal muscles. ${ }^{(23)}$ Usually, a single group of muscle is affected, but in $12-40 \%$ of cases multiple groups are involved either sequentially or simultaneously. ${ }^{(3)}$ The three clinical stages are described in table $4^{(24)}$.

Table 4: Clinical stages of tropical pyomyositis and differentials

\begin{tabular}{|c|c|c|c|}
\hline & Invasive & \begin{tabular}{|ll}
$-\quad$ & bacterial seeding \\
- & localised muscle \\
pain & swelling - tender \\
& with wooden \\
consistency. \\
Aspiration yields \\
no pus. \\
\end{tabular} & $\begin{array}{l}\text { - Muscle strain, } \\
\text { contusion }\end{array}$ \\
\hline 2. & $\begin{array}{l}\text { Suppurativ } \\
\mathrm{e}\end{array}$ & \begin{tabular}{|l} 
- \\
- $\begin{array}{l}\text { Abscess within the } \\
\text { muscle } \\
\text { Aspiration yields } \\
\text { pus }\end{array}$ \\
\end{tabular} & $\begin{array}{ll}- & \text { Deep vein } \\
\text { - } & \text { Seprombosis } \\
\text { - } & \text { osteomyelitis } \\
\end{array}$ \\
\hline 3. & $\begin{array}{l}\text { Septicaem } \\
\text { ic stage }\end{array}$ & $\begin{array}{ll}- & \text { Bacteremia with } \\
\text { multiorgan } \\
\text { dysfunction. } \\
\text { - } & \text { Septic shock } \\
\text { - } & \text { Metastatic } \\
& \text { abscess }(\mathbf{2 5 , 2 6 )}\end{array}$ & \begin{tabular}{|l} 
- \\
gataneous \\
misdiagnosed \\
as necrotising \\
fasciitis
\end{tabular} \\
\hline
\end{tabular}

Aspiration of pus from the muscle or muscle biopsy (in cases of absent macroabscesses in early invasive stage) with culture and tissue staining is the gold standard for diagnosis. But in tropic region pus culture are sterile in $15-30 \%$ of cases, whereas $90-95 \%$ of patients in tropics and $70-80 \%$ of patients in temperate regions have sterile blood culture.

Table 5: Tissue diagnosis of Pyomyositis in tropics vs temperate region- a comparision

\begin{tabular}{|l|c|c|}
\hline & Tropical & Temperate \\
\hline $\begin{array}{l}\text { Staph aureus in } \\
\text { abscess }\end{array}$ & $90 \%$ & $75 \%$ \\
\hline Sterile pus culture & $15-30 \% \%^{(27)}$ & \\
\hline Sterile blood cultures & $90-95 \%^{(12-16,25)}$ & $70-80 \%$ \\
\hline Positive blood culture & $5-10 \%$ & $20-30 \%$ \\
\hline
\end{tabular}

Radiologically Ultrasound is the initial tool for screening the purulent stage of pyomyositis where it shows diffuse muscle hyperechogenicity with or without localized Hypoechoic areas (suggestive of collection) with an increase in muscle bulk and diffuse hyperaemia. ${ }^{(29)}$ Computed tomography/ magnetic resonance imaging (MRI) are best for early diagnosis. Contrast enhanced Computed tomography shows areas of low attenuation with loss of muscle planes and a surrounding rim of contrast enhancement as characteristic of pyomyositis. It differentiates tumours, haematoma, and thrombophlebitis from abscess. ${ }^{(21,29)}$ Magnetic resonance imaging is gold standard for diagnosis of pyomyositis at any stage.It can differentiate pyomyositis from necrotising soft tissue infections. The MRI shows hyperintense rim on $\mathrm{T} 1$ weighted images with peripheral enhancement on gadolinium DTPA scan (gadolinium - diethylenetriaminepentaacetic acid) ${ }^{(30)}$. Gallium scintigraphy is an extremely sensitive tool, utilised for detecting unsuspected but possible metastatic abscess.

Laboratory investigations reveal anaemia, leucocytosis, increased ESR, and APR. Serum levels of muscle enzymes - aldolase, creatine phosphokinase, aminotransferase, and lactic dehygrogenase - are normal or slightly raised due to muscle destruction. Raised CPK along with characteristic electromyographic changes (short duration, low amplitude polyphasic potentials), confirms the diagnosis of polymyositis. Deranged liver and renal functions, along with fever and severe diffuse myalgia, suggest leptospirosis which is further confirmed by serological tests. Immunodeficient states such as HIV, diabetes, rheumatological disorders, and malignancies should be ruled out. ${ }^{(29)}$ In our case, the incidental finding of deep venous thrombosis led us believe that it was the root cause of all problems of our patient. The fact that it was rather a consequence of infection was realised later when the evaluation for pulmonary thromboembolism was negative and hence diagnosis of pyomyositis was made.

In a rare scenario, the case may present like toxic shock syndrome. ${ }^{(31)}$ At times the invasive stage may get prolonged as pyrexia of unknown origin. When it is localised to neck muscles, it can be misdiagnosed for cervicobrachial neuralgia. ${ }^{(32)}$ 
Therefore, tropical pyomyositis should be considered and ruled out in any patient presenting with muscle pain, fever, and/or leucocytosis.

One of the important differentials in this case was Paget- schroetter syndrome, which is a venous form of thoracic outlet syndrome (vTOS), classically occurs in the dominant arm of young athletes. Its pathophysiology involves compression of the neurovascular bundle exiting from the thoracic outlet, by repetitive motion of the upper extremity, resulting in venous microtrauma and subsequently perivenous fibrosis thereby leading to activation of the coagulation cascade. The subclavian vein is most common vein to get involved. Common symptoms include unilateral upper extremity pain, swelling, and arm fatigue. Facial plethora and chest wall edema is seen, if the more proximal superior vena cava (SVC) is involved. The most commonly used diagnostic modality is venous duplex ultrasonography, which shows loss of compressibility of the vein and lack of color Doppler flow within the venous lumen. Spectral analysis shows reduced or absent respiratory phasicity which is suggestive of proximal obstruction. Compared to lower extremity DVT, UEDVT has a lower risk of embolism to the pulmonary vasculature, whereas clinically apparent pulmonary embolism (PE) occurs in 5$8 \%$ of patients with a mortality of $0.7 \%$ and subclinical PE in $36 \%$ of patients.

The mainstay of treatment in primary UEDVT is prompt anticoagulation, aiming at early venous recanalization, to be initiated with catheter directed thrombolytics (CDT). Anticoagulation should be continued for at least 3 months with either low molecular weight heparin (LMWH), vitamin $\mathrm{K}$ antagonists, or direct oral anticoagulants (DOACs). The most recent updates to ACCP guidelines recommend anticoagulant therapy alone over thrombolysis. ${ }^{(33)}$ However, thrombolysis can be considered in patients with severe symptoms, extention of thrombus from subclavian to axillary vein, symptoms $<14$ days, good performance status, life expectancy $>1$ year, and low risk for bleeding. ${ }^{(34)}$

The basic modalities of treatment include supportive therapy, antibiotics, anticoagulation and surgical drainage/ debridement. If identified at first stage, antibiotic therapy covering Gram positive organisms is sufficient while in immunocompromised patient, additional gram negative coverage is given. In later stages, broad spectrum antibiotics covering gram positive including MRSA and gram negative organisms are used empirically, which can be escalated or deescalated as per culture reports. ${ }^{(29)}$ For HIV infection and immunosuppressed patients, broad spectrum empirical antibiotics against Gram positive, Gram negative and anaerobic organisms should be administered. In addition to antistaphylococcal antibiotics, patients should also receive aminoglycosides and clindamycin. Clindamycin is indicated in severe cases of necrotising infections, toxic shock syndrome. ${ }^{(29)}$ (table 6)

Treatment should be tailored to clinical and radiographic features. The nasal carriage, in patients with pyomyositis or bacteraemic staphylococcal infection, should be treated with topical mupirocin nasal formulation. Alternatives include rifampicin (600 $\mathrm{mg}$ each day) or cloxacillin (500 mg four times a day) for 10 days. $^{(35)}$

Table 6: antibiotic coverage in c/o pyomyositis

\begin{tabular}{|c|c|c|}
\hline Organisms & Antibiotics recommended & Dose \\
\hline $\begin{array}{l}\text { Staph } \\
\text { sensitive) }\end{array}$ & $\begin{array}{l}\text { Parenteral } \\
\text { antistaphylococcal } \beta \text { - } \\
\text { lactamase resistant } \\
\text { penicillin- cloxacillin(32) }\end{array}$ & $\begin{array}{l}1-2 \mathrm{~g} \text { every six } \\
\text { hours }\end{array}$ \\
\hline $\begin{array}{l}\text { Methicillin resistant } \\
\text { staphylococcus }\end{array}$ & $\begin{array}{l}\text { Vancomycin } \\
\text { Teicoplanin }\end{array}$ & $\begin{array}{l}-15 \mathrm{mg} / \mathrm{kg} \text { to a } \\
\text { max of } 1 \mathrm{~g} \text { every } \\
12 \text { hourly } \\
-400 \mathrm{mg} / \text { day in a } \\
\text { single dose }\end{array}$ \\
\hline $\begin{array}{l}\text { Vancomycin } \\
\text { intermediate sensitive } \\
\text { staphylococcus }\end{array}$ & $\begin{array}{l}\text { Linezolid } \\
\text { Dalfopristine-quinapristine }\end{array}$ & \\
\hline Group A streptococcus & Crystalline penicillin & \\
\hline Gram negative bacilli & $\begin{array}{l}\text { Cephalosporins } \\
\text { Gentamicin }\end{array}$ & $\begin{array}{l}-5-6 \mathrm{mg} / \mathrm{kg} / \mathrm{day} \\
\text { iv }\end{array}$ \\
\hline Anaerobic infection & Metronidazole & $\begin{array}{l}-20-30 \\
\text { mg/kg/day iv or } \\
\text { orally } \\
\text { hourly }\end{array}$ \\
\hline
\end{tabular}




\section{Conclusion}

Early diagnosis is critical for saving the life of patient but it is often missed because of unfamiliarity with the disease, atypical presentations, a wide range of differential diagnoses, and lack of early specific signs. The natural history is progressive suppuration with either spontaneous drainage and gradual resolution or eventual bacteraemia, and secondary infection leading to fatal outcome. Despite advances in diagnosis and treatment, mortality of pyomyositis varies from $0.5 \%$ to $2 \%$. The initiation of therapeutic anticoagulation along with intravenous antibiotics remains controversial, where the risk of anticoagulation, metastatic spread of septic emboli, spontaneous resolution of thrombus even without anticoagulation should be considered. Whether anticoagulation is beneficial for antibiotic penetration into the septic emboli resulting in faster resolution of thrombus is debatable.

\section{Financial Support and Sponsorship: Nil}

Conflicts of Interest: There are no conflicts of interest.

\section{References}

1. Chauhan S, Jain S, Varma S, Chauhan SS. Tropical pyomyositis (myositis tropicans): current perspective. Postgraduate Medical Journal [Internet]. 2004 May 1 [cited 2018 Dec 8];80(943):267-70. Available from: https://pmj.bmj.com/content/80/943/267

2. Meena M, Harish S, Kewlani JP, Gupta N, Meena VK. Paget-Schroetter Syndrome. Chin Med J (Engl) [Internet]. 2015 Oct 5 [cited 2018 Dec 7];128(19):2694-5. Available from: https://www.ncbi.nlm.nih.gov/pmc/articles /PMC4736857/

3. Chiedozi LC. Pyomyositis. Review of 205 cases in 112 patients. Am J Surg. 1979 Feb;137(2):255-9.
4. Chauhan S. Tropical pyomyositis (myositis tropicans): current perspective. Postgraduate Medical Journal [Internet]. 2004 May 1 [cited 2018 Nov 21];80(943):267-70. Available from: http://pmj.bmj.com/cgi/doi/10.1136/pgmj. 2003.009274

5. Traquair RN. Pyomyositis. J Trop Med Hyg. 1947 May;50(5):81-9.

6. Bonafede $\mathrm{P}$, Butler $\mathrm{J}$, Kimbrough $\mathrm{R}$, Loveless M. Temperate zone pyomyositis. West J Med. 1992 Apr;156(4):419-23.

7. Diamandakis V, Grose C. Bad consequences of bicycle accidents: Pyomyositis. Pediatric infectious disease journal. 1994;13(5):422-425.

8. Jayoussi R, Bialik V, Eyal A, Shehadeh N, Etzioni A. Pyomyositis caused by vigorous exercise in a boy. Acta Paediatr. 1995 Feb;84(2):226-7.

9. Temperate pyomyositis in an injecting drug misuser. A difficult diagnosis in a difficult patient | Emergency Medicine Journal [Internet]. [cited 2018 Dec 17]. Available from: https://emj.bmj.com/content/20/3/299?ijke $\mathrm{y}=65 \mathrm{a} 05 \mathrm{ac} 96051 \mathrm{bc} 494 \mathrm{~b} 88 \mathrm{e} 20 \mathrm{~b} 419 \mathrm{f} 3 \mathrm{a} 277$ 17bfd72\&keytype2=tf_ipsecsha

10. Christin L, Sarosi GA. Pyomyositis in North America: case reports and review. Clinical infectious diseases. 1992;15(4):668-677.

11. Sarubbi FA, Gafford GD, Bishop DR. Gram-negative bacterial pyomyositis: unique case and review. Reviews of infectious diseases. 1989;11(5):789-792.

12. Minami K, Sakiyama M, Suzuki H, Yoshikawa N. Pyomyositis of the vastus medialis muscle associated with Salmonella enteritidis in a child. Pediatric radiology. 2003;33(7):492-494.

13. Wolf RF, Konings JG, Prins TR, Weits J. Fusobacterium pyomyositis of the shoulder after tonsillitis: Report of a case of Lemierre's syndrome. Acta 
orthopaedica

Scandinavica.

1991;62(6):595-596.

14. Tuberculous pyomyositis in an immunosuppressed patient [Internet]. [cited 2018 Dec 17]. Available from: http://www.scielo.org.co/scielo.php?script =sci_arttext\&pid=S0120-

41572016000500004

15. Fincher R-ME, Jackson MW, Fischer AQ. Case report: Citrobacter freundii: a newly reported cause of pyomyositis. The American journal of the medical sciences. 1990;299(5):331-333.

16. Brook I. Pyomyositis in children, caused by anaerobic bacteria. Journal of pediatric surgery. 1996;31(3):394-396.

17. Smith IM, Vickers AB. Natural History of 338 Treated and Untreated Patients with Staphylococcal septicaemia (1936-1955.). Lancet. 1960;1318-22.

18. Miyake H. Beitrage zur Kenntnis der sogenannten Myositis infectiosa. Mitt Grenzgeb Med Chir. 1904;13:155-198.

19. Hall RL, Callaghan JJ, Moloney E, Martinez S, Harrelson JM. Pyomyositis in a temperate climate. Presentation, diagnosis, and treatment. J Bone Joint Surg Am [Internet]. 1990 Sep [cited 2018 Dec 17];72(8):1240-4. Available from: http://europepmc.org/abstract/med/239809 4

20. Idoko JA, Oyeyinka GO, Giassudin ASM, Naida A. Neutrophil cell function and migration inhibition studies in Nigerian patients with tropical pyomyositis. Journal of Infection. 1987;15(1):33-37.

21. Rodgers WB, Yodlowski ML, Mintzer CM. Pyomyositis in patients who have the human immunodeficiency virus. Case report and review of the literature. JBJS. 1993;75(4):588-592.

22. Musculoskeletal manifestations in patients positive for human immunodeficiency virus: correlation with CD4 count. The Journal of Rheumatology [Internet]. [cited
2018 Dec 17]. Available from: http://www.jrheum.org/content/28/4/802?ij key $=40 \mathrm{c} 40$ eed $527 \mathrm{ab} 0 \mathrm{f} 9 \mathrm{c} 4 \mathrm{fc} 7 \mathrm{a} 20 \mathrm{be} 8817 \mathrm{cb}$ 2ae1fda2\&keytype2=tf_ipsecsha

23. Ashken MH, Cotton RE. Tropical skeletal muscle abscesses (pyomyositis tropicans). British Journal of Surgery. 1963;50(226):846-852.

24. Chukawama CL. Pyomyositis. Am J Surg. 1979;137:255-9.

25. Gambhir IS, Singh DS, Gupta SS, Gupta PR, Kumar M. Tropical pyomyositis in India: a clinico-histopathological study. The Journal of tropical medicine and hygiene. 1992;95(1):42-46.

26. Andy JJ, Ekpo EB. Cardiovascular complications of tropical pyomyositis. Tropical and geographical medicine. 1987;39(3):260-264.

27. Shepherd JJ. Tropical myositis: is it an entity and what is its cause? The Lancet. 1983;322(8361):1240-1242.

28. Brown JD, Wheeler B. Pyomyositis: report of 18 cases in Hawaii. Archives of internal medicine. 1984;144(9):1749-1751.

29. Mathew UE, Ray A, Soneja M, Vyas S, Sanker K, Nischal N, et al. Pyomyositis Complicated by Deep Venous Thrombosis-A Unique Case of Reverse Lemierre's Syndrome. Journal of The Association of Physicians of India. 2017;65:87.

30. Soler R, Rodríguez E, Aguilera C, Fernández R. Magnetic resonance imaging of pyomyositis in 43 cases. European journal of radiology. 2000;35(1):59-64.

31. Immerman RP, Greenman RL. Toxic shock syndrome associated with pyomyositis caused by a strain of Staphylococcus aureus that does not produce toxic-shock-syndrome toxin-1. The Journal of infectious diseases. 1987;156(3):505-507.

32. Flory P, Brocq O, Euller-Ziegler L, Ziegler G. Pyomyositis: cervical localization. The 
Journal of rheumatology. 1993;20(8):1411-1413.

33. Upper Extremity Deep Vein Thrombosis [Internet]. American College of Cardiology. [cited 2019 Jan 10]. Available from:

http $\% 3 \mathrm{a} \% 2 \mathrm{f} \% 2 \mathrm{fwww}$.acc.org\%2flatest-incardiology $\% 2$ farticles $\% 2 \mathrm{f} 2017 \% 2 \mathrm{f} 11 \% 2 \mathrm{f0}$ 9\%2f $13 \% 2 \mathrm{f} 30 \% 2$ fupper-extremity-deepvein-thrombosis

34. Upper Extremity Deep Vein Thrombosis [Internet]. American College of Cardiology. [cited 2019 Jan 10]. Available from:

http $\% 3 a \% 2$ f $\% 2$ fwww.acc.org $\% 2$ flatest-incardiology $\% 2$ farticles $\% 2 \mathrm{f} 2017 \% 2 \mathrm{f} 11 \% 2 \mathrm{f0}$ $9 \% 2 \mathrm{f} 13 \% 2 \mathrm{f} 30 \% 2$ fupper-extremity-deepvein-thrombosis

35. Chauhan S, Jain S, Varma S, Chauhan SS. Tropical pyomyositis (myositis tropicans): current perspective. Postgraduate medical journal. 2004;80(943):267-270. 